\title{
The Value Assessment and Enlightenment about the Reform of Civil Service Recruitment System in Britain and America in the New Era
}

\author{
Jun Dai \\ Department of Public Administration, Shaanxi Normal University, Xi'an, China \\ E-mail: daijun2100@163.com
}

\begin{abstract}
This paper sets up the analysis framework from the fundamental value of civil service recruitment system of efficiency, social equity, political responsiveness and individual value, then gives value assessment of civil service recruitment system in Britain and America in the new era, explores the value orientation and value consensus of reform in Britain and America, and then reveals its characteristics and regularities. Research discovers that the general tendency of civil service recruitment system in Britain and America can be depicted as: efficiency is the uppermost value; political responsiveness and social equity are in the next place, whereas individual right value is weakened, the tension between multiple values achieve its dynamic balance through the counter-balance of value.
\end{abstract}

Keywords-Civil Service Recruitment; Value Assessment; Value Balance

\section{INTRODUCTION}

The civil service system in Britain and America are rather perfect and representative in the world. Recent years in Britain and America, with the transition from industrial society to post-industrial society, the in-depth continuity of globalization as well as the development of modern technology, traditional civil service system has gradually exposed its limitation, which causes British and American governments confronting universal financial crisis, managerial crisis, and trust crisis. In order to solve aforementioned problems, Britain and America have implemented important reform to the civil service system based on modern technology as well as theoretical guidance of the new public management theory and modern human resource management theory, which has definitely made achievements, but also brings series of disputes. The design of civil service employment system is the operational beginning and nuclear content of civil service system. Institutional design is the specific performance of policy, which reflects its value connotation and preference.

\section{VAlUE ORIENTATION AND PRACTICAL FORM OF THE CIVIL SERVICE RECRUITMENT SYSTEM}

Scholars at home and abroad hold several of viewpoints about the value orientation of public personnel administration. According to the key points of reform of civil service system in Britain and America, this paper borrows Klingner and Nalbandian's viewpoint which includes the orientation of "four fundamental social value" from the research perspective of civil service recruitment system, it means "Public Personnel Management" can be deemed as a continuous interaction phenomenon that the four fundamental social values always clash each other. The four values are political responsiveness, efficiency, individual right, social equity. These values practice through relative personnel institution to satisfy various functions of personnel. [1] However, the value sequence and manifestation of the aforementioned four values possess differences in different eras and countries. Generally speaking, improving administrative efficiency and ensuring social equity play the leading role during the recruitment of civil service system, whereas political responsiveness and individual right are in a secondary value orientation. In the process of civil service recruitment, these values concrete connotation and manifestation are shown like followings:

Efficiency Value. During recruitment, efficiency value indicates its recruitment decision should be based on applicants' knowledge, skill, and capability. Recruitment policy corresponding with efficiency value should make sure the lowest cost and highest efficiency, it can identify the most excellent applicant rapidly, and then offer managers flexible space, so that they can compete with other competitors in the market. Thus, efficiency value possesses two implications in recruitment policy: Firstly, it contains persons who can find organization demands quickly and use the method of money. Secondly, people who are employed by organization should satisfy its demands in knowledge, skill and capability to improve work efficiency. Efficiency value differs in policy and practice pattern in different eras. The forms of efficiency value under recruitment policy include flexible design of recruitment relationship, personnel distribution system based on position classification, decentralization in recruitment pattern and flexible recruitment methods, etc. [2]

Social Equity Value. Social equity consists of program equity, interaction equity, essence equity in the recruitment process. Program equity mainly talks about whether recruitment process conforms to public competition, equal chance, and relief afterwards. Interaction equity relates to how the rater and manager execute procedure rules and spirits fairly and selflessly during the process of procedure. Essence equity indicates the relative adaptability between examination system and applicant's capability and trait; the matching degree between employees and position; thereby it can ensure that employees possess competent capabilities than those who are not employed. Essence equity always be investigated through validity and reliability. [3]In order to achieve aforementioned objective, implemental policies 
include equal recruitment opportunity, preferential schemes for vulnerable groups, etc.

Political Responsiveness Value. Political responsiveness value mainly consists of two intensions in the process of recruitment: One is the manner and criterion of recruitment should accord with the demand of political heads. The other is the selected person can respond to policies of political heads effectively, and can also close to people's requirement. For the sake of achieving aforementioned objectives, we always practice it through the political application of position, increase on politics-appointment person, and recruitment criterion of political loyalty.

Individual Right Value. Individual right value emphasizes legal safeguard that individuals should possessed, if deprived, it needs justifiable procedure norm. Individual right value mainly includes permanent recruitment relationship, adoption of proper legal procedure and collective negotiation institution in recruitment policy. Klingner and Nalbandian deem that individual right value has similarities with contribution principle and social equity value actually. The practice of western civil servant system revolution indicates that permanent employment relationship has gradually replaced by contract relationship, as for collective negotiation institution, because labor-capital relations transfer from contradiction to cooperation, thus its development space in employment policy areas of public sector has shrunk widely, in addition, individual right value mainly occurs in the process of promotion and dismissal, therefore, this paper fails to give key discussion on collective negotiation institution in the process of civil servant employment system.

\section{The Value Assessment of Civil Service RECRUITMENT SYSTEM IN BRITAIN AND AMERICA}

\section{A. Efficiency Value Highlights Its Leading Position in Recruitment Policy Gradually}

The major purpose of the reform in Britain and America is to improve governmental efficiency and effectiveness, which its core route is the transition from traditional types based on norm, centralization to promote efficiency consistently to flexible, decentralized, multiple recruitment pattern to improve efficiency. Its value form briefly performs in flexible design of recruitment relationship, decentralized recruitment pattern and flexible recruitment method.

On Basis of Insisting on Permanent System to Strengthen Flexible Recruitment Method Furtherly. Recent years, Britain and America emphasis the flexibility of recruitment relations, claiming that other than long-time recruitment pattern, it should implement contractual human resource which is full-time, part-time, temporary or outsourcing. The general tendency of government' recruitment relationship is flexibility, which embodies permanent career employee decreasing gradually, nonpermanent temporary employee and exempt employee expanding step by step. The policy performs in two sides: one is the simplification of recruitment procedure and rules; the other is the emphasis on flexibility of qualification.
America carries out "National Performance Review Project" in Bill Clinton Age, which abolishes the "Personnel Management Rules Handbook" with thousands of pages, simplified as a new handbook with a thousand of pages. Regulation simplification aims to increase decentralization space of managers and their flexible behaviors, rather than abandon fundamental principles of the civil service system. Meanwhile, carrying out flexible policies of qualifications in terms of recruitment rules. The government carries out "The President's Management Agenda" in Bush Age, they aim to establish a civil service system which can adopt to any situation and adopt to different mission, culture, flexibility as well as sensitivity, response of employee structure in different administrative organ by the way of implementing flexible policy and experimental engineer. Additionally, offering maximum flexibility to administrative organ and its leaders when not endanger or damage the core value of institution. [4]

British government released White Paper on Civil Service System: Taking forward Continuity and Change in 1996, which gives large revolution to civil service system. It refers to selection, recruitment, wage of civil service system, for example, all civil services should sign objective management contract with government sector, civil service is no longer permanent and senior civil service group will be established.

Taking the Operational Optimization of Examination Right as Core, Increasing Recruitment Sovereignty of Government Sector Continuingly. Although the centralization of selection powder brings affirmation of equity, this pattern is not favorable of the improvement of effectiveness and efficiency due to the change of environment. Britain and America's civil servant recruitment system has experienced revolution course from traditional function integrated type to function distributed type. Decentralization indicates delegating the selection and recruitment rights to every sector, these sectors recruiting and employing by themselves. In addition, the obligation of federal personnel management office has changed as policy planning, supervising and assisting. This decentralized strategy takes efficiency as the most significant factor, which includes saving time and cost of distinguishing and supplying, and then they are eager to ensuring all the employees accord with organ's demands by virtue of the actual participation in selection of all employers.

The report "Reinventing Human Resource Management" of Clinton Government points out that "Reinventing human resource management should redefine obligation according to outcome, and implement reform on basis of authority decentralization, weaken regulation, simplification, flexibility and expand essential delegation". During reform of civil service recruitment system, it should change the previous regulation that personnel management office exercises recruitment power with centralization and unification, and then by the method of delegation to make federal government sectors and organs possess larger autonomy of civil service recruitment, so that it can enhance the capability of managing civil service groups for federal government, sectors and organs. From 1990s to the early 
21 st century, administrative position in federal government has more than 80 percent achieve it through decentralization. [5]

Britain proceeded personnel decentralization by virtue of civil service of the Privy Council in 1995, which summited personnel issues that originally belonging to financial department to each department directors. The selection of civil service is no longer centralized management as long as conform the principle of equity and publicity, its procedure and skill emphasize the mechanism of selecting talents professionally.

Perfect the Procedure and Method of Recruitment, Pay More Attention to Outcome-Oriented other than ProcessOriented. When refers to reform of recruitment method, the general tendency of Britain and America claims for recruitment hierarchy, form diversification and scientification of evaluation technique.

In Britain, except for traditional written examination and interview, they also innovate pattern of recruitment continuingly. The civil service committee issued Recruitment Code in 2006, each hierarchy of civil service recruitment opened completely; open and competitive recruitment method has become popular. Diversification in recruitment forms, implementation of some new techniques and methods, such as Fast Stream, E-Recruitment Project, 360-Degree Feedback, career management help improving efficiency of recruitment. [6]

For the sake of attracting excellent talents, at the beginning of Obama's assumption of duty, he formulates President Memorandum. By improving procedure and method of civil service recruitment further to enhance the quality and efficiency of recruitment, so that it can ensure to attract high-quality talents for federal governments. Obama puts forward a recruitment method "End-To-End" which embodies great highlights. Its key point lies in enhancing recruitment efficiency and quality of civil service. End-ToEnd recruitment method includes 5 procedures: Workforce Planning-Recruiting-Hiring Process-Security-Orientation, whose concrete implemental procedure is made up of 14 links, each link has specific time demand of totally 80 days. [7]

\section{B. On Basis of Insisting on Practicing Program Equity to Emphasis Substantial Equity of Recruitment}

When social equity value applies to recruitment policy, the negative level indicates hope to establish an equal competitive environment in order to achieve the target of equal recruitment. What's more, the positive level prefers to offer preferential recruitment policies to vulnerable groups and those who are discriminated in our society during the past time, which is called vulnerable groups action scheme. The value of social equity emphasizes representativeness of gender, ethnic group, and psychosomatic-disorder person at present.

The Insistence and Development of Public Competition Principles. Although British civil service system has experienced huge alteration, the public competition principle of selecting person should also be persisted. They emphasis not only competition, but also public and complete competition. Meanwhile, expanding scope of recruitment. When it is vacancy of junior civil service in Britain, they mainly adopt the method of recruiting from society, while for senior civil service; they prefer the method of internal promotion to supply the vacancy. But recent years, Britain begins to selecting senior civil service from society, additionally; the vacancy candidates in America expand from 3 to 7 when selecting civil services. America focuses more on the equity of opportunity for people both inside and outside the civil service system. The candidates of senior position are no longer limited to senior civil service, majority of positions are available to all society. There are no strict regulations in qualification and age when it refers to selection and recruitment, which provides people equal competition opportunity of different ages and qualifications.

Continuing Preferential Schemes of Vulnerable Group, Paying More Attention to the Diversification and Representativeness of Recruitment. Britain issued The White Book of Cabinet Office in 1999, they consider that civil service system must promote diversity policy positively to reflect actual situation of society, which consists of enhancing job opportunity of vulnerable group such as female, minority groups, and psychosomatic disorder. In addition, it also demands to provide psychosomatic disorder person adjustment of work conditions to improve work efficiency that needed to overcome in working environment. British vice prime minister put forward a social mobility strategy named Opening Doors, Breaking Barriers in 5th, April, 2011. Its mission lies in eliminating job unfairness due to the differences of states and fortune between social members, of which the Whitehall Internship Scheme has already started as one of the component of social flow strategy in July, 2011.

Providing stable occupation for people who are most desirable for job as wide as possible is the recruitment principle of American government. Those who are in huge desire for job include low-academic-degree person, disabilities, aged person, minorities and people who lose competition in workplace. This principle of recruitment cause to low efficiency of government sector in a degree, but it brings an advantage of stabilizing society.

\section{Maintaining Permanent System at the SAME TIME, IMPROVING THE POLITICAL RESPONSIVENESS VALUE BY MEANS OF SETTING UP SENIOR CIVIL SERVICE AND FLEXIBLE RECRUITMENT SYSTEM}

The selection of western civil service emphasis responsiveness to society and politics. Responsiveness of politics means the establishment of senior civil service, while social responsiveness indicates more social stratum people entering into civil service team. The highlighted performance is shown like the followings: Firstly, increasing political employees, strengthening the control to civil service. Britain and America hope to offer inducement and career development to senior civil service besides the civil service system, so that the government can operate effectively, besides, they prefer to make permanent civil service to response policy objective and guidance of politicsappointment officials. [8] Secondly, recruitment criterion of 
political loyalty, Presently, American federal code stipulates that the federal personnel management office should precede loyalty investigation to representatives or its agents, $R \& D$ employees, national defense personnel. Loyalty investigation of public services that are recognized as engage in high-level important or sensitive jobs should be charged of Federal Bureau of Investigation.

\section{Regulation of Value Transition: Tension and DyNamic Balance BeTween PluRal Value}

\section{A. Value \&Practice Dilemma of British and American Civil Service Reform}

The civil service system is deemed as a structure of conflict and interaction between four fundamental social values. It may weaken public administration's core value of continuity, neutrality, contributions because of the revolution of British and American civil service recruitment system. What's more, it might damage significant, even permanent high-level political value such as democracy, equity, justice, clean, rule by law, power balance. [9] Except for shortening the selecting period, whether decentralized operation can decrease the cost of selection, and if they can find out persons who are required by organ actually still exits dispute. Contractual labor can bring lots of flexibility to organization, adjust to personnel demand rapidly, however, it indeed exits many shortcomings, such as high ratio of turnover, difficult management, low organizational commitment and loyalty, poor working quality, etc. It is more likely to breeding corruption and influencing social equity by loosening regulation, weakening heteronomy, and relying on officials' personal quality and moral cultivation too much in administrative validity and rationality.

\section{B. Plural Value Proceeds New Value Ranking through Value Counterweight}

Elliott points out that, in the process of public personnel administration value, the leading value performs different with time goes by. After this, the previous leading value has not disappeared, but only weakened. So the value of public personnel administration will be calculated continuingly, presenting the situation of multi-dispute. [10] Among the four demand values, it will always appear some relationships with conflict and tension, which reflects the value orientation and political presentation in dynamics. Firstly, emphasizing a certain value unilaterally will result in institutional distortion. Klingner and Nalbandian suppose that if putting any value of civil service system into an extreme situation and compressing space of other value will make the efficiency of human resource management distorted. We can discover that it presenting a dynamic balance and nervous relationship of conflicting value, if any value put into extreme situation extruding other values' space, the value itself will lose its utility and result in institutional distortion, which is called counter value. Among the four values, efficiency-first recruitment policy might cause a morbid state such as setting objectives, elitism, abuse of management power, etc. These morbid issues should be dissolved under the assistance of political responsiveness value, social equity value and individual right value. The lopsided development of political responsiveness value might bring morbid affaires such as sharing the spoils and political application of civil service, which can be responded with the promotion of efficiency and individual right. The extremeness of social equity value might cause problems like anti-discrimination and the capability deficiency of employees, which can be balanced by the emphasis of individual right and efficiency. The extremeness of individual right value might bring negative phenomenon such as energy of manager, individualism, which can be responded with political responsiveness, efficiency and social equity. [11]

\section{SUMMARY}

In a word, reform of Britain and America is proceeding now; there are many disputes among theoretic and practical. The dispute is actually a clash between Bureaucracies and post-bureaucracy, whose general tendency is the process from personnel administration management to human resource management. The ideal balance situation of value is the complementation and combination among each value, so as to achieve the core objective by arranging the most excellent talents to the most suitable position.

\section{ACKNOWLEDGMENT}

This paper is supported by the Social Science Fund Project of Shaanxi Province in 2013 (13E007) , 2015 SNNU Funded International visiting scholar Project, Educational Reform of Graduate Student, SNNU, 2015 （GERP-15-15).

\section{REFERENCES}

[1]. Donald Klingner, Hohn Nalbandian, "Public Personnel Management: system and strategy", 6th ed., Taylor \& Francis, 2009, pp. 8-12.

[2]. Zhongyong Xiong, "The Study on reform of civil service recruitment policy in Britian and America: viewpoint of policy value", Ph.D. dissertation, National Chengchi University, China, 2005.

[3]. Nengjie Shi, "The assessment of civil service recruitment system", Taiwan politics journal, pp.170-172, June, 2003.

[4]. USDA Human Capital Conference, Accountability in Human Capital Management Transformation \& Modernization Initiatives, Mar. 2003.

[5]. Pennsylvania State University, U.S Department of Agriculture Personnel Management Demonstration Project Second Annual Evaluation Report ,Pennsylvania State University, p. 22, April 1993.

[6]. Civil Service Management Code: 1.Taking up appointment, 1.5 Fast Stream Development Program, 1.5.3.

[7]. White House. Briefing Room, Presidential Actions, Presidential Memorandum. http://www.whitehouse.gov/the-pressoffice/presidential-memorandum-improving-federal-recruitmentand-hiring-process, 11th, May 2010.

[8]. Nigro, Lloyd G. and Felix A. Nigro. The New Public Personnel Administration. 4th ed., Itasca, Illinois: F. E. Peacock, 1994, p. 40.

[9]. Bo Yang, "Institution reform and value conflict: Comment on reform of civil service system in western countries recent years", Nanjing Social Science, vol.5, pp.48-52, 2002.

[10]. Elliott, Robert H., Public Personnel Administration: A Values Perspective. Reston, VA: Reston, 1985. 